\title{
DILMA VS TEMER: O QUE FOI PROMETIDO E O QUE REALMENTE MUDOU PARA O MERCOSUL?
}

\author{
Ana Carolina dos Santos Costa ${ }^{1}$ \\ Victor Tavares Barbosa ${ }^{2}$
}

\begin{abstract}
Resumo
O presente trabalho se propõe a investigar como as mudanças na política interna no Brasil, a partir de 2011 até o fim do governo Temer, em 2018, interferiram na postura do Brasil para com Mercosul. Para responder à pergunta deste trabalho pretendemos aliar os métodos de análise qualitativa com análise quantitativa de dados. Por um lado, utilizaremos a análise de conteúdo para entender os objetivos de cada presidente. Para Dilma I e II analisaremos as suas propostas de governo para a política externa brasileira (PEB) frente ao Mercosul. Para Temer, buscaremos os seus posicionamentos públicos sobre a PEB com relação ao Mercosul durante o processo de impeachment. Então, após identificar esses padrões, iremos nos debruçar sobre a quantidade dos acordos bi e multilaterais assinados por cada governo no âmbito do Mercosul para então entender se as mudanças na política externa foram pragmáticas ou programáticas.
\end{abstract}

Palavras-chave: Mercosul; política externa brasileira; Dilma; Temer.

Dilma vs Temer: What was promised and what really changed for Mercosur?

\begin{abstract}
This paper aims to investigate how the changes in domestic politics in Brazil, from 2011 until the end of the Temer government, in 2018, interfered in Brazil's stance towards Mercosur. To answer the question of this work we intend to combine the methods of qualitative analysis with quantitative analysis of data. Firstly, we will use content analysis to understand the objectives of each president. For Dilma I and II, we will analyze her government proposals for Brazilian foreign policy (PEB) vis-à-vis Mercosur. For Temer, we will seek his public positions on PEB in relation to Mercosur during the impeachment process. Then, after identifying these patterns, we will look at the number of bi and multilateral agreements signed by each government within the scope of Mercosur to then understand whether the changes in foreign policy were pragmatic or programmatic.
\end{abstract}

Keywords: Mercosur; Brazil's Foreign Policy; Dilma; Temer

\footnotetext{
${ }^{1}$ Ana Carolina Costa: Bacharel em Ciência Política. É Pesquisadora Associada ao IEÁSIA (Instituto de Estudos da Ásia - UFPE) e Mestranda no Programa de Pós-Graduação em Ciência Política pela Universidade Federal de Pernambuco (PPGCP-UFPE). Disponível em: scostacarolina@gmail.com 2 Victor Barbosa: Mestrando no Programa de Pós-Graduação em Ciência Política pela Universidade Federal de Pernambuco. Pesquisador associado ao IEASIA. Disponível em: victortavares.b@gmail.com
} 


\section{Introdução}

A noção que as relações internacionais e as políticas domésticas interagem agudamente é quase que um consenso dentro da academia, e isso é evidenciado em trabalhos como o de Milner e Keohane (1996), Putnam (1988), Milner (1997) e Gourevitch (2002). Desde de 2015, o Brasil passa por uma série de acontecimentos que abalaram as estruturas da política doméstica do país e que são determinantes tanto para a formulação da política externa brasileira quanto sobre a maneira a qual os demais parceiros $e$ atores internacionais enxergam e se envolvem com o Brasil, em uma relação que liga a política doméstica ao contexto internacional. Logo, este trabalho busca responder a seguinte pergunta: como as mudanças na política interna no Brasil entre 2011-2018 interferiram no Mercosul?

Durante o processo de impeachment da ex-presidenta Dilma Rousseff, seus correligionários e aliados políticos apresentavam vários motivos pelos quais tal processo não deveria ser finalizado. Para além dos questionáveis porquês jurídicos envolvendo o processo, alguns dos motivos políticos alegados afirmavam que tal processo seria danoso à posição que o Brasil exercia de líder regional e protagonista político. Uma das líderes do Partido dos Trabalhadores na época chegava a dizer que o então presidente interino Michel Temer ameaçava a existência do Mercosul3. Portanto, buscamos entender se houve mudanças programáticas entre os governos Dilma e o governo Temer que alteraram 0 processo de integração entre os membros do bloco. Os autores acreditam que não, as mudanças que ocorreram foram mais programáticas do que práticas.

Este trabalho busca perceber os efeitos do processo de ruptura na política externa brasileira para com o Mercosul. A seguir, o presente trabalho está dividido em quatro sessões: primeiro temos a revisão de literatura que traz os principais debates teóricos sobre os temas abordados neste trabalho, em seguida trazemos a sessão metodológica que explica como a pesquisa foi feita, ademais apresentamos os resultados encontrados e, por fim, elaboramos algumas conclusões sobre o tema.

Neste trabalho, para responder o questionamento levantado, utilizamos uma metodologia mista. Um dos métodos utilizados foi a

\footnotetext{
3 "Gleisi Hoffmann acusa o governo Temer de colocar o Mercosul em risco". Fonte: Agência Senado. Disponível em <https://www12.senado.leg.br/noticias/materias/2016/07/07/gleisi-hoffmann-acusa-Ogoverno-temer-de-colocar-o-mercosul-em-risco> Acessado em: 30/08/2019
} 
análise de conteúdo, que pode ser definida em linhas gerais como a análise sistemática, objetiva e quantitativa das características da mensagem. Ideal para a utilização em discursos políticos, tal qual foi usada neste trabalho. A análise de conteúdo é um método de pesquisa que utiliza um conjunto de procedimentos para fazer inferências válidas do texto. Há consenso entre pesquisadores que as características distintivas da análise de conteúdo são que ela deve ser objetiva, sistemática e quantitativa (KASSARJIAN, 1997; NEUENDORF, 2012; WEBER,1990).

Tendo em vista a literatura firmada sobre o tema, fizemos a extração de todos os discursos da então presidenta da República Dilma Rousseff que diziam respeito a política exterior e ao Mercosul disponíveis no site da Biblioteca da Presidência ${ }^{4}$, fizemos a limpeza de formatação para arquivos " $t x f$ " e, em seguida, os dados foram analisados através do Iramuteq ${ }^{5}$, uma interface auxiliar do software Rstudio, específica para análise de conteúdo. O mesmo foi feito para a análise dos discursos de Michel Temer. No que diz respeito às variáveis de estatística descritiva, utilizamos os dados sobre os acordos e tratados firmados pelo Mercosul durante o período estudado e os mesmos foram extraídos do site oficial do Itamaraty. As estatísticas sobre as trocas comerciais têm como fonte o atual Ministério da Economia, Indústria, Comércio Exterior e Serviços. Optamos por trazer a análise dessas duas variáveis pelo amplo consenso na bibliografia específica que as mesmas são imprescindíveis para a análise do tema, ademais, são dados norteadores que podem atestar se o que foi analisado nos discursos pode, de fato, ser observado na prática.

\section{Revisão de literatura}

\subsection{Determinantes de Política externa}

Tanto ontologicamente quanto epistemologicamente, há uma tendência em abordar as políticas domésticas e internacional enquanto elementos distintos. Por conseguinte, criou-se dentro da Ciência Política duas subdisciplinas: a Política Comparada, para lidar com os fenômenos que ocorrem dentro do Estado e as Relações Internacionais, por sua vez, voltada para o estudo dos laços entre Estados (AMORIM NETO \& MALAMUD, 2015). Enquanto a hierarquia e o monopólio da violência caracterizam a primeira, a anarquia e as configurações variáveis de poder distinguem a

\footnotetext{
${ }^{4}$ Biblioteca da Presidência da República. Disponível em: <http://www.biblioteca.presidencia.gov.br/> Acessado em 30/08/2019.

${ }^{5}$ Interface auxiliar do R para análise de conteúdo. Disponível em <http://www.iramuteg.org/>. Acessado em: 30/08/2019.
} 
segunda. Dessa forma, a política externa compõe uma área de interseção, uma vez que é uma política pública desenvolvida dentro do Estado e a principal contribuição da política internacional. (AMORIM NETO \& MALAMUD, 2015).

Khara et al (2018) elenca dois conceitos como alguns dos determinantes para a política externa, são eles opinião pública e interesses. O autor aponta que a opinião pública é uma preocupação de longa data para Estados, uma vez que gera pressões normativas que influenciam a política externa. Por exemplo, Dilma Rousseff, foi de boa gestora a incompetente na opinião pública ${ }^{6}$. A baixa popularidade e a necessidade de buscar apoio internacional na crise do impeachment a fez, enquanto Presidenta da República, adaptar à política externa brasileira uma diplomacia midiática em uma tentativa de mudar a opinião que a comunidade internacional tinha sobre a sua gestão e o Brasil (CIRINO, LEITE e NOGUEIRA, 2019). Por sua vez, frente a baixa popularidade das gestões anteriores, Temer tentou se distanciar do que foi adotado em Dilma na política externa (OLIVEIRA, 2018). Então, percebe-se que a opinião pública exerceu um papel central na construção da política externa nesse período.

Outro ponto importante, ressaltado por Khara et al (2018), são os interesses. Os formuladores de política externa avançam da preocupação com interesses individuais para a preocupação com os interesses dos grupos. Os assuntos domésticos e internacionais, seus arranjos e seus detalhes sociais relacionados permanecem como a plataforma na qual a formulação da política externa ocorre, no entanto, parte dos interesses agregados (KHARA et al, 2018). Dessa forma, interesses distintos dos formuladores de política levam a políticas externas distintas, como é o caso de Dilma e Temer. Essa questão será melhor explorada na seção com a análise dos programas de governo dos presidentes.

Os componentes determinantes da política externa são de dois tipos: internos e externos. Os determinantes internos incluem território, fatores geográficos, culturais, históricos, econômicos, tecnológicos, capacidades nacionais, estrutura social, sistema de partidos políticos, lideranças, responsabilidade política, imprensa e burocracia (KHARA et al, 2018, p. 113). Já os determinantes externos incluem organizações e instituições internacionais, percepção de outros países, posição no nível internacional, opinião pública no nível internacional e agrupamentos (Khara et al, 2018). Então,

\footnotetext{
6 "Dilma foi de boa gestora a incompetente na opinião pública", EXAME, 2016, Disponível em: <https://exame.com/brasil/depois-de-fama-de-boa-gestora-dilma-deixa-planalto-sob-ataques-deincompetencia/> Acessado em 15/04/2020.
} 
mesmo que a ruptura política interna tenha impactado o Mercosul, é preciso destacar que outros fatores internos do Brasil bem como elementos externos também influenciaram o bloco. E essa é uma das limitações explicativa da nossa pesquisa. Não podemos inserir todas as variáveis possíveis no modelo e não podemos controlar a distribuição de causas potenciais, ciente dessas limitações, nosso modelo tem como foco, apenas o discurso dos mandatários brasileiros que assumiram o poder no nosso recorte temporal. A análise dos discursos destes, é importante para compreender $\mathrm{O}$ comportamento de um ator político (o Brasil), frente ao bloco.

\subsection{Política externa de Dilma e Temer}

Pondo em xeque a política externa desenvolvida durante 0 governo Dilma I, após uma análise baseada no modelo de Hermann (1990) - que propõe classificações para as causas das mudanças de política externa e para as mudanças em si, Cornetet (2014) defende que a política externa do governo Dilma I segue os mesmos padrões estabelecidos nas gestões do presidente Luiz Inácio, isto é, o foco estava no desenvolvimento pela diversificação de parceiros e o estabelecimento do Brasil enquanto uma potência e liderança regional. No entanto, como aponta a pesquisa do autor, a política externa de Dilma investiu nesses propósitos com menos empenho e ativismo, o que caracteriza uma contenção dos esforços na diplomacia brasileira (CORNETET, 2014).

Cornetet (2014) chegou a esses resultados através da comparação da quantidade de viagens internacionais presidenciais dos três primeiros anos dos dois mandatos de Lula e o primeiro de Rousseff, dos países e territórios visitados bilateralmente pelos presidentes, das ações e iniciativas deles no âmbito da política externa, da quantidade de vagas ofertadas pelo Instituto Rio Branco e o crescimento anual das representações diplomáticas brasileiras no exterior. Assim, tendo em vista que um dos fatores marcantes da política externa brasileira e da diplomacia presidencial são as viagens internacionais dos presidentes, no primeiro mandato de Rousseff, a maioria das visitas da presidenta foram para países latino-americanos, principalmente, integrantes do Mercosul. $\mathrm{Na}$ quantidade de destinos de viagem, a Argentina ocupa o primeiro lugar com o maior número de visitas, três. Já a Venezuela e o Paraguai estão na segunda posição, com duas visitas cada (CORNETET, 2014). Mas comparado aos governos petistas anteriores, houve uma diminuição na quantidade de viagens internacionais, o que indica um distanciamento de Rousseff da diplomacia 
presidencial e um maior foco na política interna vis-à-vis a externa (CORNETET, 2014).

Cornetet (2014) aponta que tal contenção ocorreu devido ao viés administrativo da presidenta bem como em consequência da configuração do cenário internacional naquele momento - uma profunda crise econômica e instabilidade em termos de segurança em algumas regiões, que por sua vez, limitavam o campo de ação da política externa brasileira (CORNETET, 2014).

Com relação a uma política econômica externa, Dilma também manteve um ambiente de continuidade das gestões de Lula, apontam Bastos e Hiratuka (2017). A atenção construída nos anos de Lula para a política de integração regional autônoma aos Estados Unidos e voltada para o Sul global foi mantida. Isso pode ser exemplificado com a incorporação da Venezuela, em 2012, ao Mercosul e a inserção da África do Sul aos BRICS, em 2011 (BASTOS \& HIRATUKA, 2017).

Ao balancear as relações entre o Brasil e o Mercosul nos governos de Rousseff (2011-2016), em uma análise de conjuntura a partir de uma revisão bibliográfica, Desiderá Neto (2017) levanta que houve uma diminuição de esforços, no que cabe à administração brasileira, para a criação ou melhoria das instituições pertinente ao processo de integração regional. Como aponta o autor, a única ação no Mercosul a qual o governo brasileiro se debruçou sobre foi a retomada das negociações com a União Europeia. Outras questões importantes, como aprovar a eleição direta de mercodeputados ou internalizar o Código Aduaneiro Comum, não avançaram, principalmente, devido às problemáticas internas do país (DESIDERÁ NETO, 2017).

Nesse tocante, Desiderá Neto (2017) destaca que as particularidades do cenário político interno em crise foram barreiras que impediram, de certa forma, o avanço dos esforços brasileiros para com o Mercosul, mas que os desdobramentos na alçada do ambiente internacional também dificultaram a situação. À exemplo, ocorreram o impeachment do presidente paraguaio Fernando Lugo em 2012, a escala de políticas protecionistas na Argentina, crise política na Venezuela e, para além da América do Sul, o cenário também era de crise econômica. Tais eventos se colocaram no caminho do avanço das instituições de integração regional (DESIDERÁ NETO, 2017). Então, é importante ressaltar que uma diminuição do engajamento brasileiro no Mercosul não é fruto apenas de circunstâncias internas do Brasil, as idiossincrasias 
regionais exercem um papel de saliência, e esse é uma das limitações da nossa pesquisa.

Então, de forma geral, percebe-se uma continuidade da política externa brasileira de Lula à Rousseff, apesar da abordagem da presidenta ser mais contraída que a do seu antecessor. Com a crise política que culminou no impeachment de Rousseff em 2016 e o estabelecimento de Michel Temer na posição de Presidente da República, essa continuidade foi rompida. Assim, a chegada de Temer ao poder trouxe uma ideia de ruptura na política externa brasileira (SILVA, 2019).

Essa ruptura pode ser descrita em termos de mudança e implementação da política externa. Por exemplo, a primeira decisão de Temer foi não nomear um diplomata de carreira para o cargo de Ministro das Relações Exteriores, indicando José Serra, político filiado ao PSDB, para a posição de Chanceler. Em sua posse, Serra expôs suas intenções de traçar uma política díspar das efetuadas nos governos petistas. Nas palavras do então Chanceler:

[...] A diplomacia voltará a refletir de modo transparente e intransigente os legítimos valores da sociedade brasileira e os interesses de sua economia, a serviço do Brasil como um todo e não mais das conveniências e preferências ideológicas de um partido político e de seus aliados no exterior. A nossa política externa será regida pelos valores do Estado e da nação, não do governo e jamais de um partido. Essa nova política não romperá com as boas tradições do Itamaraty e da diplomacia brasileira, mas, ao contrário, as colocará em uso muito melhor. [...] (BRASIL, 2016)

Utilizando como aporte teórico o modelo de Hermann (1990), assim como fez Cornetet (2014) para os governos Lula e Rousseff, Silva (2019) ressalta que o propósito da política externa no governo Temer era a busca por investimentos, alicerçada na construção da imagem do Brasil enquanto um país defensor da ordem internacional vigente. Por sua vez, Oliveira (2018) destaca que ao tentar se distanciar do modelo adotado nas gestões passadas, as novas diretrizes da política externa brasileira da gestão Temer passaram a pôr em xeque algumas alianças internacionais e, por conseguinte, os seus critérios. Nesse viés, destaca-se a "revisão" das relações Venezuela-Brasil. Como aponta Oliveira (2018), alguns dos porquês por trás de tal reformulação residem no fato dela simbolizar uma investida contra a herança do Partido dos Trabalhadores bem como atraía o eleitorado contrário ao PT.

No que diz respeito ao Mercosul, assim como aconteceu nos governos Dilma, a política externa de Temer também focou no 
acordo comercial com a União Europeia (UE), aproveitando o novo fôlego que o bloco recebeu após a concretização do chamado Brexite investida da UE de não demonstrar ter ficado abalada com o caso (OLIVEIRA, 2018).

Comparando quatro pontos principais da gestão Temer às de Lula e Rousseff (a participação na política externa, a delegação do cargo de Ministro das Relações Exteriores, as relações com a Venezuela e a participação das organizações internacionais), a partir de uma revisão bibliográfica, Oliveira (2018) argumenta que a política externa brasileira em Temer apresentou traços de uma política pública negligenciada, pois mesmo privilegiando relações comerciais e econômicas, atuou de forma discreta nos demais tocantes da política externa, como é o caso das Organizações Internacionais.

Percebe-se uma prevalência da revisão de bibliográfica como método de análise da política externa brasileira, mesmo quando em uma perspectiva comparada. Isso pode ser resultado de uma escassez de pesquisas voltadas a análise comparada das políticas externas de Dilma e Temer no momento. Tendo isso em mente, resolvemos ir mais a fundo na história política do Brasil e revisar a literatura de outra situação de ruptura política - a transição do governo Fernando Henrique Cardoso (FHC) para o Lula. Ressaltamos que nosso foco aqui é destacar como a ruptura foi abordada na literatura e os principais resultados sobre seu impacto na mudança da política externa brasileira.

Trabalhos como o de Vigevani e Cepaluni (2007), por exemplo, que buscam comparar a PEB de FHC e Lula, além de utilizarem a revisão de literatura como ferramenta metodológica principal, o fazem levando em consideração muitas variáveis, como a posição dos presidentes em relação a Área de Livre Comércio das Américas (ALCA), combate à fome internacional, Conselho de Segurança, cooperação sul-sul, Estados Unidos, integração latino-americana, entre outros. Assim, os autores afirmam que elementos externos, como o ataque terrorista de Sete de Setembro, exerceram um papel importante na transformação da PEB de FHC para Lula. No entanto, não acreditam que a ruptura política, por si só, mesmo com a mudança dos perfis ideológicos dos principais policymakers tenha determinado alterações na política externa brasileira. Então, de acordo com Vigevani e Cepaluni (2007), em comparação com a de Fernando Henrique Cardoso, a política externa de Lula apresenta uma continuidade, mesmo com alguns ajustes e mudança de programa. 
Em sintonia com Vigevani e Cepaluni (2007), tanto em termos metodológicos - revisão bibliográfica com foco em vários pontos da política externa dos presidentes como a ALCA, o Mercosul e segurança -, quanto nos resultados da pesquisa, Sales (2007) expõe que a política externa de Lula não reflete exatamente uma quebra com as desenvolvidas nos governos anteriores, mas a PEB assumiu uma nova orientação em Lula. Os principais eixos da política externa brasileira foram mantidos, no entanto, o papel desempenhado pelo país de líder regional e dos países em desenvolvimento, com a ênfase dada a integração da América do Sul e o acordo entre as nações emergentes para agirem de forma conjunta na Organização Mundial do Comércio - o G-20, trouxe inovações para a PEB (SALES, 2007).

Nessa perspectiva, Villa e Vianna (2007) reforçam que, com a chegada de Lula ao poder, a política externa brasileira não passou por uma ruptura completa com relação a exercida por seu antecessor Fernando Henrique Cardoso. Manteve-se, então, certos níveis de continuidade na gestão de Lula da política externa, retendo alguns elementos basilares das gestões de FHC, no entanto, executando as metas de inserção internacional de maneira mais clara e com um grau de ativismo (VILLA \& VIANNA, 2007).

Por sua vez, Villa e Neiva (2011), em uma análise comparativa do discurso dos presidentes Fernando Henrique e Lula com o uso da análise de conteúdo como ferramenta metodológica, argumentam que a economia exerceu um papel central na política externa de ambos os presidentes, enquanto em termos temáticos, a democracia esteve mais presente nos pronunciamentos de FHC, a desigualdade social teve lugar de destaque nas falas de Lula. Quanto às relações do Brasil com outros Estados e regiões, os autores apontam que FHC focou nos países europeus e Lula, por outro lado, nas nações africanas. Então, percebe-se que houve uma mudança no discurso em sintonia com os perfis ideológicos\programáticos de cada um dos presidentes, no entanto, como apontam Vigevani e Cepaluni (2007), Sales (2007), e Villa e Vianna (2007) as mudanças foram mais programáticas do que práticas, não simbolizando uma ruptura.

Com isso, vale ressaltar que nosso desenho de pesquisa leva em consideração um modelo de análise diferenciado. Haja visto o extenso número de contribuições que analisam a política externa de FHC e Lula, e focam em outros aspectos da política comparada. Aqui, optamos por focar nos governos mais recentes de Dilma e Temer, bem como optamos por nos debruçar por outra unidade de análise: os seus respectivos discursos, buscando trazer uma 
contribuição diferenciada a literatura vigente. Apresentamos na seção seguinte nossos resultados encontrados.

\section{Resultados}

\subsection{Análise Documental:}

\subsubsection{Programas de Governos}

Em seu programa de governo, para a gestão 2011-2014, a coligação "Para o Brasil seguir mudando" de Dilma Rousseff registrou junto ao Tribunal Superior Eleitoral suas propostas. No documento ${ }^{7}$ há planos referentes a diversas searas, no entanto, no que tange ao Mercosul, pouco foi proposto. Uma das ideias englobava as questões de Direitos Humanos e proteção de homens, mulheres e jovens. Assim, em seu plano de governo, Rousseff propôs fortalecer a atuação internacional do Brasil na defesa dos Direitos Humanos em organizações internacionais como as Nações Unidas e o Mercosul.

Para além desse ponto, o Mercosul foi mencionado apenas mais uma vez, referenciando o aprofundamento da integração regional do bloco. Deste modo, no texto, Dilma promete que, em associação dos os demais países, avançar o processo de integração do Mercosul, resolvendo divergências e pendência e fortalecendo a sua institucionalidade.

Já para sua gestão de 2015-2018, que foi interrompida em decorrência do impeachment, o programa de governo de Rousseff faz uma única menção ao Mercosul. Nele, a coligação "Com a força do povo" afirma que dará continuidade a prioridade à América do Sul, ao se comprometer em fortalecer o Mercosul, a Unasul e a Comunidade dos Países da América Latina e Caribe (CELAC), sem discriminação de ordem ideológica. Afirma também que o Brasil buscará antes de tudo a integração da região, por meio do fomento do comércio e da integração produtiva. E finaliza a menção prometendo que dará ênfase especial à integração financeira e de suas infraestruturas física e energética do Mercosul, Unasul e CELAC.

\footnotetext{
7 O programa de 2010 não estava publicado na plataforma do PT. Este foi extraído de jornais que publicaram a notícia na época. Disponível em: <https://www.conjur.com.br/dl/propostas-dilmaatualizado.pdf> Acessado em 01/09/2019.

${ }_{8}^{8}$ Programa extraído da plataforma do PT. Disponível em <https://www.pt.org.br/wp-

content/uploads/2014/07/Prog-de-Governo-Dilma-2014-INTERNET1.pdf> Acessado em 01/09/2019
} 
No que tange ao mandato de Michel Temer, seu programa de governo ${ }^{9}$ per si, já é um documento polêmico, que causou controvérsia na opinião pública, publicado em meio à crise política da segunda gestão de Dilma. É uma carta-compromisso publicada para a sociedade civil que apresenta os principais pontos do que seria a gestão interina de Michel Temer, mas que não foi legitimada através de eleições. Neste documento também só há uma única menção ao Mercosul, que é feita ao tratar sobre as propostas para a economia brasileira, e promete realizar a inserção plena da economia brasileira no comércio internacional, com maior abertura comercial e busca de acordos regionais de comércio em todas as áreas econômicas relevantes com Estados Unidos, União Europeia e Ásia, com ou sem a companhia do Mercosul, embora preferencialmente com eles.

Ao observar o conteúdo das mensagens passadas pelos três programas governamentais, é possível observar grandes divergências. Se por um lado, entre Dilma 2010 e 2014 há uma diminuição de menções. Há também uma evolução qualitativa nas mensagens passadas: no primeiro programa a menção sobre aprofundamento da integração é pouco explicativo, enquanto a menção aos Direitos Humanos pouco diz respeito aos mecanismos de integração do bloco. Já no programa de 2014, apesar de uma única menção, a mesma é mais assertiva em relação a ênfase e a prioridade que os processos de integração como o Mercosul terão no governo enquanto mecanismo de crescimento econômico. A menção do programa de 2014 acaba por especificar melhor qual a intenção para o Mercosul neste segundo governo.

Em ambos os programas de Dilma fica clara a prioridade que os blocos econômicos como o Mercosul terão em seu governo. Entretanto, este ponto se torna uma chamativa diferença no programa apresentado por Michel Temer, que deixa claro que o os mecanismos de integração não mais seriam a prioridade do governo. O foco para a recuperação econômica brasileira se daria através das relações com os países do norte do hemisfério e com a região da Ásia, porém não mais obrigatoriamente estas relações seriam de forma multilateral com a companhia do Mercosul. Em seu programa, Temer explicita que o Brasil trilharia seu caminho, independente da presença do Mercosul.

Tendo em vista que estas foram mensagens passadas ao povo brasileiro antes que ambos assumissem o cargo, faz-se necessário

\footnotetext{
9 Programa extraído do site da Fundação Ullysses Guimarães, fundação ligada ao PMDB. Disponível em: <https://www.fundacaoulysses.org.br/wp-content/uploads/2016/11/UMA-PONTE-PARA-OFUTURO.pdf> Acessado em 01/09/2019.
} 
agora debruçar-se sobre os discursos de Dilma e Temer enquanto chefes do executivo e observar se há mudanças nos padrões de discurso utilizados.

\subsection{Análise de Conteúdo: $O$ que foi dito?}

\subsubsection{Dilma (2011-2014):}

Figura 1 - As 350 palavras mais faladas por Dilma em seu $1^{\circ}$ mandato

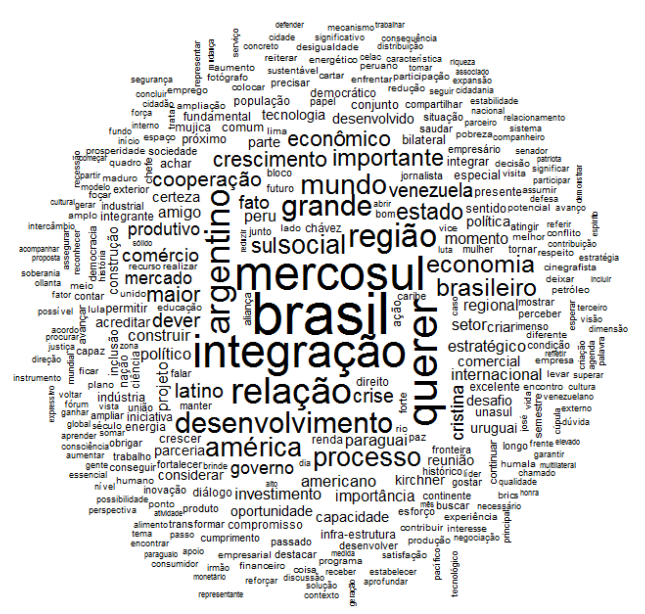

Fonte: gráfico confeccionado pelos autores, 2019.

Este primeiro gráfico trata-se de um mapeamento de todos os discursos sobre o tema feitos por Dilma em sua primeira gestão. Foram filtrados todos os discursos cujo o assunto tratava o Mercosul. No total, foram 33 discursos catalogados pela biblioteca da presidência ao longo de 4 anos de gestão, uma média de 8,25 discursos por ano. Sendo o ano mais ativo o de 2011, com 11 discursos, e o menos ativo o de 2014, com 4 pronunciamentos. As palavras "Brasil", "integração" e "Mercosul" são as três palavras mais repetidas por Dilma neste período. Também é possível observar a presença de palavras que passam um sentimento de otimismo como "grande", "desenvolvimento" e "querer".

Para além dos adjetivos que qualificam países, "argentino" é o que aparece com mais frequência. Também devemos notar que as palavras "cooperação", "crescimento" e "econômico" aparecem em frequências medianas. Como pode ser observado nos gráficos anuais expostos no apêndice, a Argentina aparece como principal 
parceiro (pelo menos em discurso) durante os anos de 2011 e 2012. Em 2013 o foco muda para Peru e Paraguai, mas em 2014, o foco retorna para o Mercosul enquanto bloco.

Neste primeiro período é possível inferir uma atitude e posicionamento confiante da chefe do executivo brasileiro, cujo foco dava ênfase ao período de prosperidade e estabilidade, características daquele período. Além disso, os discursos proferidos já em exercício da função apresentavam semelhança com a mensagem passada aos brasileiros através do programa de governo que prometia aprofundamento da integração regional com o Mercosul. Porém, neste período não há menções significativas sobre "direitos humanos".

\subsubsection{Dilma (2015-2016):}

Figura 2 - As 350 palavras mais faladas por Dilma durante seu $2^{\circ}$ mandato

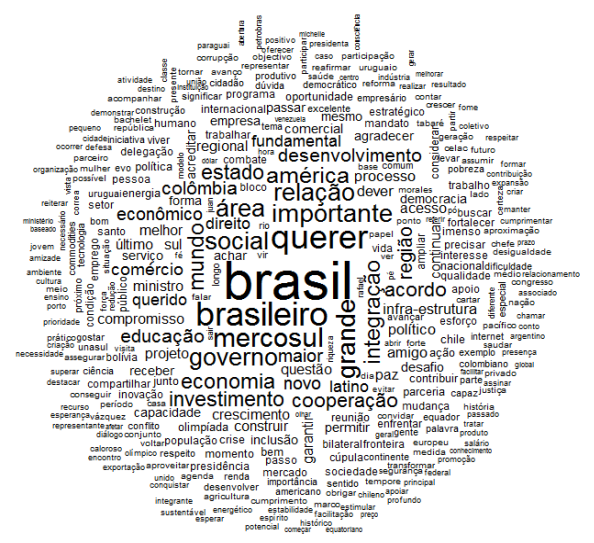

Fonte: gráfico confeccionado pelos autores, 2019

$\mathrm{Na}$ segunda gestão de Dilma, interrompida pelo processo de impeachment, foram catalogados 24 discursos que tratavam sobre - Mercosul, apresentando uma média de 12 pronunciamentos por ano. Sendo 2015 o ano de maior atividade com 16 discursos proferidos. Nesse segundo período, existe uma mudança de foco, "Brasil" figura enquanto a palavra mais repetida, seguida de "brasileiro" e só depois por "Mercosul". Também há uma segunda diferença, a frequência de adjetivos assertivos diminui, dando a lugar a maior presença de substantivas como "investimento", "governo" e "economia".

Nos gráficos individuais, presentes no apêndice, em 2015 há uma maior frequência de menções a Colômbia e, em 2016, ao Chile. 
Entretanto, os temas abordados diferem, estes deixam de ter uma abrangência de política externa no período passado como "comércio", "mercado", "integração" e "região", todos termos ligados aos processos de integração regional. Os termos para este período abrangem muito mais temas da política doméstica, havendo uma maior frequência de temas como "educação" e "social" que estão ligados a inclusão e bem-estar social. Apesar deste ser o período instabilidade de sua gestão, Dilma continuou exercendo uma diplomacia presidencial ativa, entretanto 0 conteúdo das mensagens desses discursos, não apresentam tanta semelhança com o que foi prometido em seu segundo ano de governo. Neste período, Dilma parece dar mais ênfase em legitimar sua gestão através dos discursos sobre política externa.

\subsubsection{Temer (2016-2018):}

Figura 3 - As 350 palavras mais faladas por Temer entre 2016-2018

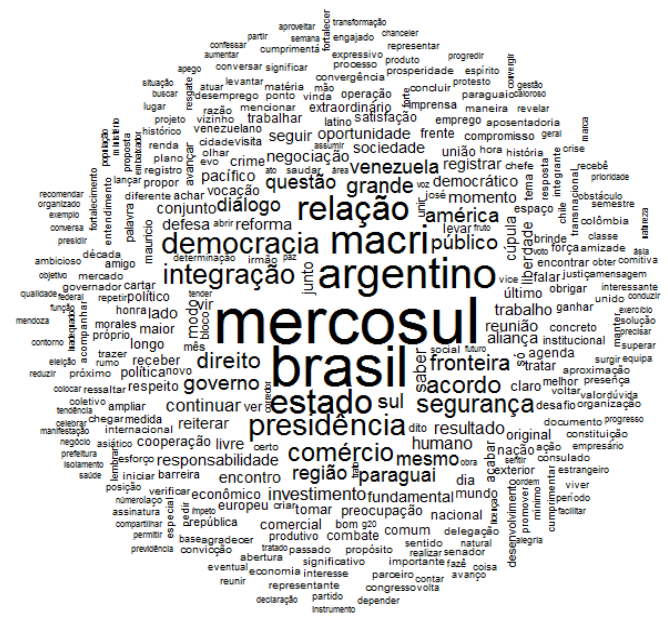

Fonte: gráfico confeccionado pelos autores, 2019

Para esta gestão foram catalogados todos os discursos que tratavam sobre Mercosul proferidos por Michel Temer, o que contabilizou 16 discursos ao longo de 3 anos, apresentando uma média de 5.3 discursos por ano. Uma média inferior à sua antecessora. Sendo o ano de maior atividade o de 2017 com 12 discursos sobre a política externa envolvendo o Mercosul, e 2018 o menor número registrado de todo o período estudado, com apenas 2 pronunciamentos. 
Neste período, as palavras mais proferidas por Temer foram "Mercosul" e "Brasil" em frequências semelhantes. Também é possível observar o retorno da importância da Argentina enquanto parceiro, havendo frequências semelhantes tanto para "Macri" (presidente argentino à época) e "argentino". Outra importante mudança sobre as gestões passadas é a maior frequência de substantivos como "democracia" e "presidência", que aparecem com maior regularidade que "integração", por exemplo.

Outra mudança perceptível é nos temas abordados. "Economia" e "investimento" diminuem as aparições, enquanto cresce a menção a "segurança". Tanto a análise de conteúdo por gestão quanto a anual, disponível no apêndice, comprovam que Temer parece utilizar seus discursos sobre política externa e aparições internacionais para legitimar sua posição enquanto novo chefe do executivo brasileiro. Menções sobre "democracia" e "presidência" se repetem em todos os anos. Ademais, o protagonismo da Argentina para as relações regionais brasileira foi retomado, se na primeira gestão de Dilma, ele foi liderado pelas duas chefes do executivo, Roussef e Kirschner, neste último período elas são retomadas por Macri e Temer.

\subsection{Análise de Estatística Descritiva}

\subsubsection{Acordos firmados com o Mercosul por gestão ${ }^{10}$}

Figura 4: Acordos do Mercosul entre 2011-2018

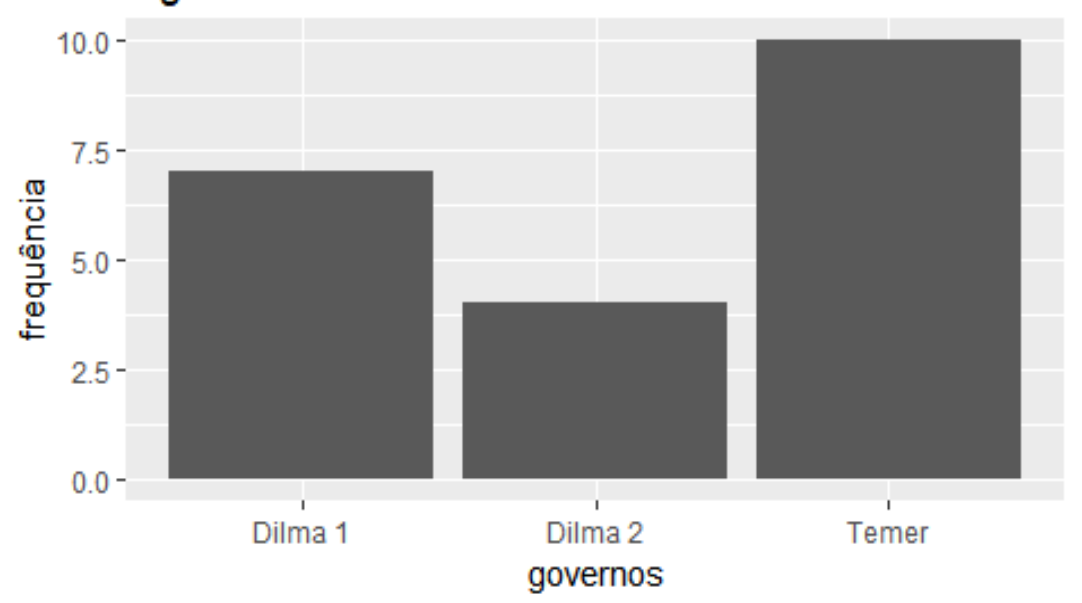

Fonte: gráfico confeccionado pelos autores, 2019

${ }_{10}$ Gráfico construído pelos autores a partir de dados fornecidos pelo Ministérios de Relações Exteriores do Brasil, disponível em: < http://www.mre.gov.py/tratados/public web/ConsultaMercosur.aspx>. Acessado em 17/08/2019. 
Na primeira gestão de Rousseff, de 2011 a 2014, um total de 7 acordos foram assinados. Muitos deles versando sobre comércio, cooperação e economia. Em seu curto e conturbado segundo mandato, houve uma diminuição na quantidade de acordos firmados. No período em questão, 2015-2016, 4 acordos foram pactuados. Em contrapartida, com a chegada de Temer à presidência da República, percebe-se um crescimento na quantidade de tratados assinados. Em dois anos, 2017 a 2018, o Brasil, junto ao Mercosul, firmou 10 compromissos. Um montante significativo se comparado com os seis anos das gestões de Rousseff e o volume de acordos que foram assinados.

\subsubsection{Fluxo comercial do bloco por ano ${ }^{11}$}

Figura 5 - Fluxo de exportações Brasil-Mercosul durante os anos 2010-2018

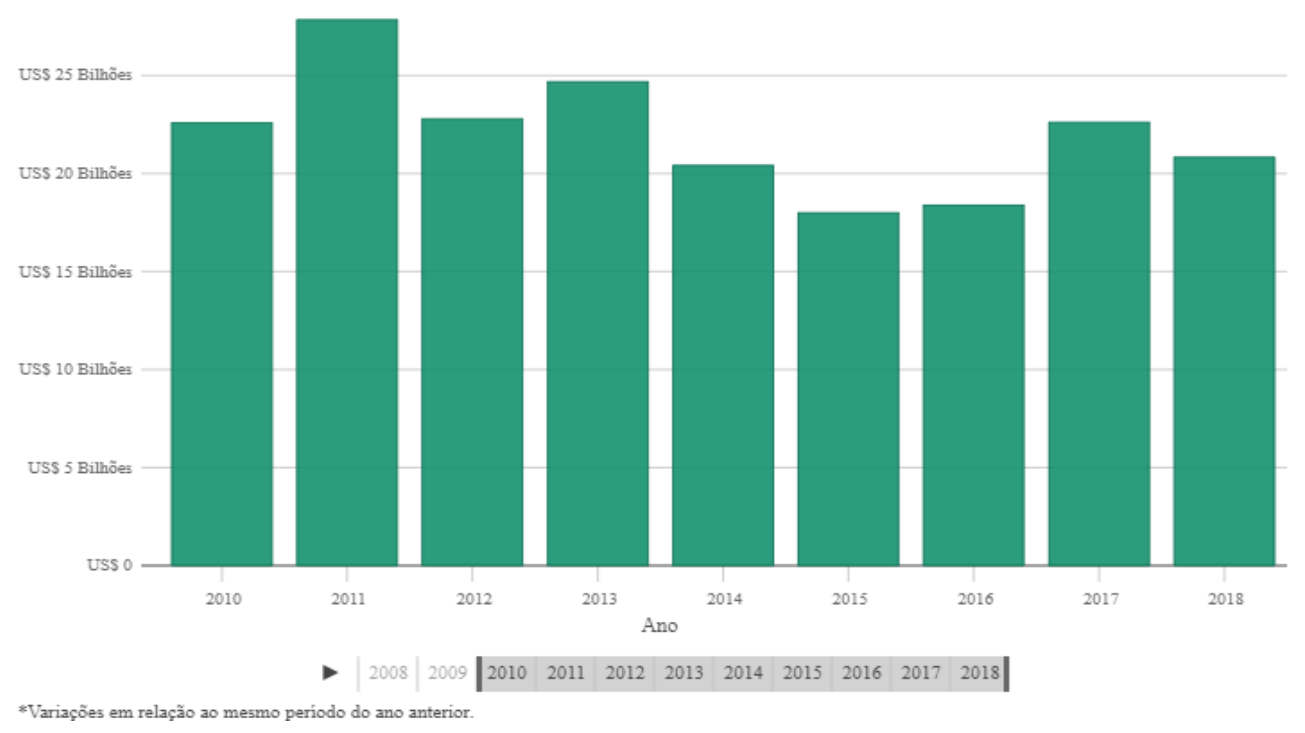

Fonte: Governo Brasileiro, 2019

Analisando o fluxo de exportações entre Brasil-Mercosul, é possível observar que 2011 é o ano de maior pico comercial com um montante na casa dos 25 bilhões em exportações. Observa-se também um pequeno declínio com o passar dos anos no fluxo de exportações, e durante a primeira a gestão de Dilma, 2014 aparece como o menor ano nas exportações brasileiras para o Mercosul. Logo em seguida, em 2015 e 2016, o fluxo de exportações se mantém estagnado na casa dos 15 bilhões. Esse é também o período de crise política para o Brasil, com o impeachment de

11 Dados extraídos do Ministério de Economia, Indústria, Comércio Exterior e Serviços. Disponível em <http://www.mdic.gov.br/comercio-exterior/estatisticas-de-comercio-exterior/comex-vis/frame-

bloco?bloco=mercosul>. Acessado em 01/09/2019. 
Dilma. Em 2017, há uma pequena recuperação e o montante de exportações retoma para os 20 bilhões, porém em 2018 já é possível perceber um novo declínio. A partir deste gráfico é possível observar que apesar do discurso confiante de Dilma entre 20112014, ao fim do período, já era perceptível uma diminuição nas exportações Brasil-Mercosul. Este padrão se mantém, especialmente no período do impeachment, mas, mesmo com a troca de governo, não é possível captar uma nova tendência positiva.

\section{Figura 5 - Fluxo de importações Brasil-Mercosul durante os anos 2010-2018}

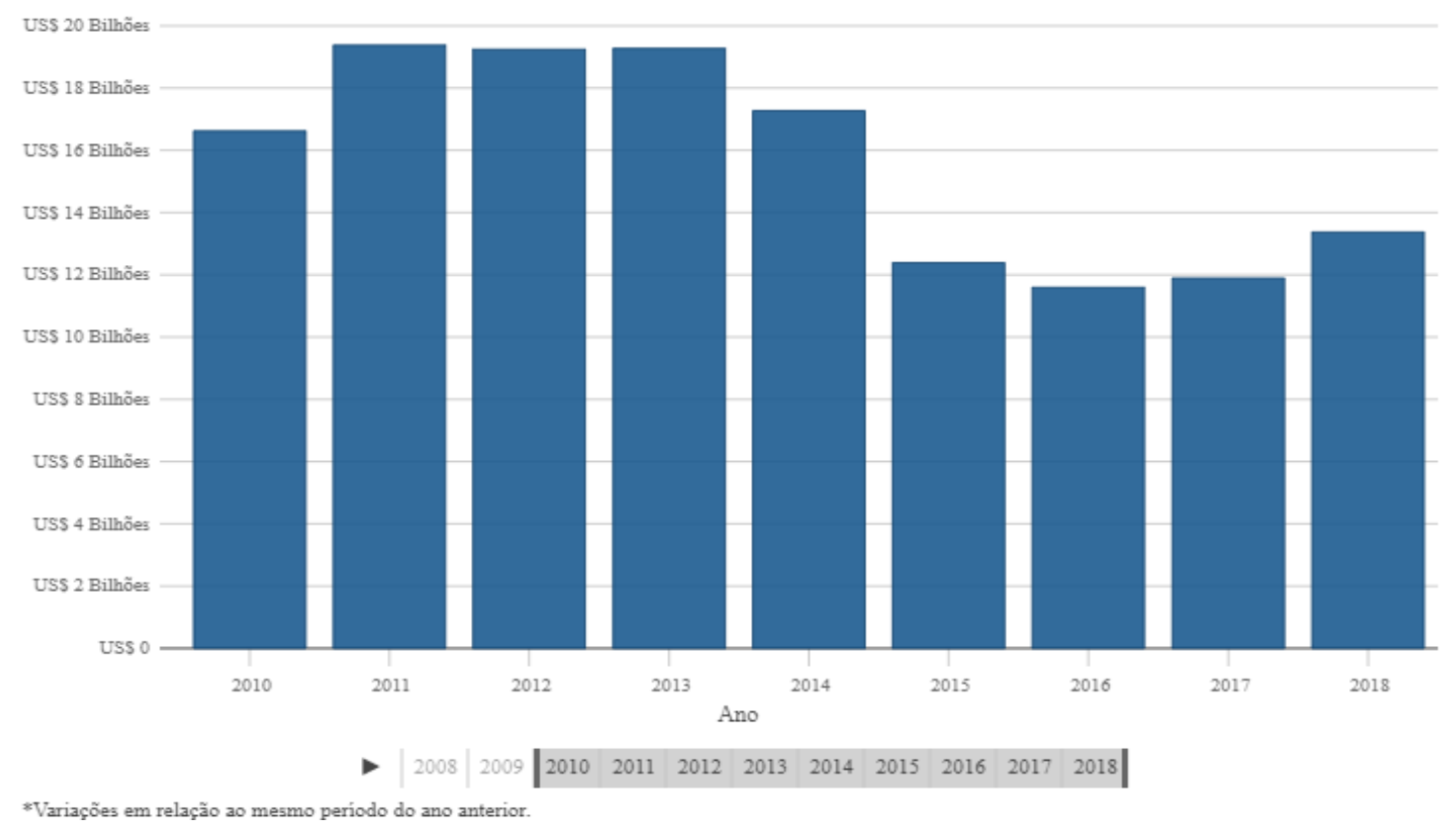

Fonte: Governo Brasileiro, 2019

Ao analisar o fluxo de importações Brasil-Mercosul podemos observar que o Brasil possui uma balança comercial favorável nesta relação, exportando produtos mais do que os importa. É possível perceber também uma estabilidade nos fluxos de importação entre 2011-2013, que são os maiores da década na casa dos 18 bilhões, havendo uma pequena diminuição em 2014. O maior declínio, no entanto, só chega entre 2015/2016, durante a crise política brasileira. E não apresenta sinais de recuperação até $O$ ano de 2018, quando registra montante na casa dos 14 bilhões, onde há um pequeno aumento, no entanto, ainda muito baixo, quando comparado ao período de 2011. O fluxo de importação pode trazer inferências sobre o poder de compra da população brasileira, ora, se o Brasil não está comprando de seus vizinhos, muito provavelmente significa que houve uma diminuição no poder de 
compra do brasileiro, trata-se de uma consequência da economia do país, abalada desde 2016, que reverbera no processo de integração econômica com os vizinhos sul-americanos.

\section{Conclusões}

Ao analisar os resultados da sessão anterior é possível observar que há diferenças nas características das gestões Dilma e da gestão Temer para o Mercosul e diferenças nos contextos econômicos dos dois períodos que afetaram o processo de integração. Porém não é possível afirmar que a gestão Temer deixou de lado por completo o processo de integração Brasil-Mercosul.

Quando comparamos as características de discurso entre os dois presidentes, é possivel afirmar que Dilma se consagrou enquanto figura assertiva, cujo discurso e meta política focavam na integração regional. Também é possível detectar uma maior diplomacia presidencial em sua gestão, uma vez que o número de aparições internacionais na região e pronunciamentos é maior que seu sucessor. A gestão de Temer não é tão coesa, se por um lado, na carta apresentada aos brasileiros ele promete desprendimento do Mercosul, o conteúdo dos seus discursos diz outra coisa, ao continuar focando na integração via Argentina enquanto parceira. Ao mesmo tempo, sua gestão aparece como campeã na assinatura de acordos do bloco. O que sugere que, mesmo com uma ruptura de governos, a burocracia especializada do Itamaraty continuou trabalhando em prol dos processos de integração em andamento.

No que diz respeito a integração econômica, a gestão Dilma consagrou-se com os melhores números, o período 2011-2014 registrou os maiores fluxos de exportação e importação entre o bloco. Enquanto Temer, que em seu programa coloca a economia como principal meta, não consegue apresentar taxas de recuperação econômica para as exportações e importações de forma tão robusta. Logo, os resultados desta pesquisa, sugerem que é possível aceitar a hipótese do trabalho de que as mudanças entre Dilma e Temer foram mais programáticas do que pragmáticas. Isto é, houve mais mudanças no discurso para a opinião pública, do que mudanças de comportamento do processo de aprofundamento da integração regional com o Mercosul. Ao contrário do que sugeriu Hoffman em 2016, Temer não destruiu o Mercosul.

Porém, a pesquisa também apresentou um comportamento inesperado, que é o papel da Argentina enquanto parceiro político 
e econômico durante todos os períodos, o que levanta a questão: qual a importância da relação Argentina-Brasil para o aprofundamento do Mercosul? Além desta também surge o questionamento sobre o poder de coesão do Itamaraty enquanto instituição e burocracia, seria ele tão forte a ponto de controlar mudanças abruptas de governo na seara da política externa? Para responder tais questões, incentivamos que novas pesquisas sobre o tema continuem sendo desenvolvidas. A convergência entre temas de integração regional, política externa e governos é extensa e muitas perguntas ainda precisam ser debatidas.

\section{REFERÊNCIAS}

BASTOS, Pedro P. Z.; HIRATUKA, Celio. A política externa do governo Dilma Rousseff: comércio, cooperação e dependência. Texto para discussão, Unicamp, n. 306, jun., 2017.

BRASIL. Ministro das Relações Exteriores. Cerimônia de transmissão de cargo Ministro José Serra. 18, maio, 2016. Disponível em: $<$ http://www.itamaraty.gov.br/pt-BR/discursos-artigos-e-entrevistas/ministro-dasrelacoes-exteriores-discursos/14038-discurso-do-ministro-jose-serra-por-ocasiaoda-cerimonia-de-transmissao-do-cargo-de-ministro-de-estado-das-relacoesexteriores-brasilia-18-de-maio-de-2016>. Acessado: 31/08/2019

CHONG, Alan. Foreign Policy in Global Information Space Actualizing Soft Power, New York: Palgrave Macmillan. 2007.

CORNETET, João Marcelo C. A política externa de Dilma Rousseff: contenção na continuidade. Revista Conjuntura Astral, v. 5, n. 24, jun/jul, 2014.

CIRINO, Thais Emmanuelle da Silva; LEITE, Alexandre César Cunha; NOGUEIRA, Silvia Garcia. Mídia e política externa brasileira: a diplomacia midiática na crise do impeachment de Dilma (2016). Intercom: Revista Brasileira de Ciências da Comunicação, v. 42, n. 1, p. 57-71, 2019

DESIDERÁ NETO, Walter Antonio. O Brasil e o Mercosul no governo Dilma (20112016). Anuario de la Integración Regional de América Latina y el Caribe, n. 14, p. 117-137, 2017.

GOLDSMITH, Benjamin E., Imitation in International Relations Observational Learning, Analogies, and Foreign Policy in Russia and Ukraine, New York: Palgrave Macmillan. 2005.

GOUREVITCH, Peter. Domestic politics and international relations. In: CARLSNAES, Walter; RISSE, Thomas; SIMMONS, Beth A. (Ed.)., Handbook of international relations, London: Sage Publication, p. 309-328, 2002.

HERMANN, Charles F. Changing course: when governments choose to redirect foreign policy. International Studies Quarterly, v. 34, n. 1, p. 3-21, 1990.

KASSARJIAN, Harold H.. Content analysis in consumer research. Journal of Consumer Research, 4, 8-18. 1977. 
KHARA, Nabin Kumar et al. Determinants of Foreign Policy: A Global Perspective. IJRAR-International Journal of Research and Analytical Reviews (IJRAR), v. 5, n. 3, p. 105-115-105-115, 2018.

MILNER, Helen V.; KEOHANE, Robert O. Internationalization and domestic politics: An introduction. Internationalization and domestic politics, p. 3-24, 1996.

MILNER, Helen V. Interests, institutions, and information: Domestic politics and international relations. Princeton University Press, 1997.

NETO, Octavio Amorim; MALAMUD, Andrés. What determines foreign policy in Latin America? Systemic versus domestic factors in Argentina, Brazil, and Mexico, 19462008. Latin American Politics and Society, v. 57, n. 4, p. 1-27, 2015.

NEUENDORF, Kimberly. The Content Analysis Guidebook (2nd ed.). Newbury Park, CA: Sage, 2012.

OLIVEIRA, Cesar A. T. A política externa do governo Temer: características e oportunidades de uma política pública negligenciada. Fronteira, Belo Horizonte, v. 17, n. 34, p. 296-309, 2018.

PUTNAM, Robert D. Diplomacy and domestic politics: the logic of two-level games. International organization, v. 42, n. 3, p. 427-460, 1988.

SALES, Camila Maria Risso. Relações internacionais e politica externa do Brasil nos governos FHC e Lula. 2007. 156 p. Dissertação (mestrado) - Universidade Estadual de Campinas, Instituto de Filosofia e Ciencias Humanas, Campinas, SP. Disponível em: <http://www.repositorio.unicamp.br/handle/REPOSIP/279401>. Acesso em: 05 março. 2020.

SILVA, Álvaro V. C. A política externa do governo Michel Temer (2016-2018): mudanças para legitimidade? Um teste da teoria de Charles Hermann. Revista Conjuntura Austral, Porto Alegre, v. 10, n. 49, p. 23-41, jan./mar., 2019.

VIGEVANI, Tullo; CEPALUNI, Gabriel. Política externa de Lula: a busca de autonomia pela diversificação. Contexto Internacional. Rio de Janeiro, vol. 29, no 2, julho/dezembro, p. 273-335. 2007.

VILELA, Elaine; NEIVA, Pedro. Temas e regiões nas políticas externas de Lula e Fernando Henrique: comparação do discurso dos dois presidentes. Revista Brasileira de Política Internacional, v. 54, n. 2, p. 70-96, 2011.

VILLA, Rafael Duarte; VIANNA, Manuela Trindade. 2. POLÍTICA EXTERNA DO GOVERNO LULA: AUTONOMIA PELA INTEGRAÇÃO OU EM BUSCA DE UM NOVO PARADIGMA. A política externa do governo Lula: 2003-2005, p. 33, 2007.

WEBER, Robert Philip. Basic content analysis (2nd ed.). Newbury Park, CA: Sage, 1990. 
6. APÊNDICE

6.1 Gráficos de Análise de Conteúdo por ano de exercício na presidência

\subsubsection{Dilma - 2011:}

Figura 1 - As 350 palavras mais faladas por Dilma em 2011

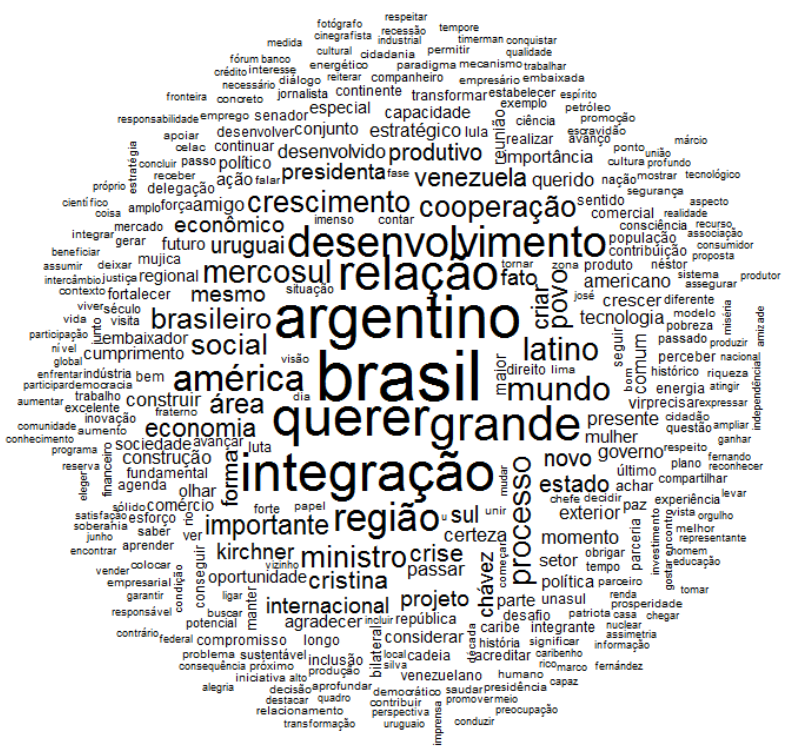

\subsubsection{Dilma - 2012:}

Figura 2 - As 350 palavras mais faladas por Dilma em 2012

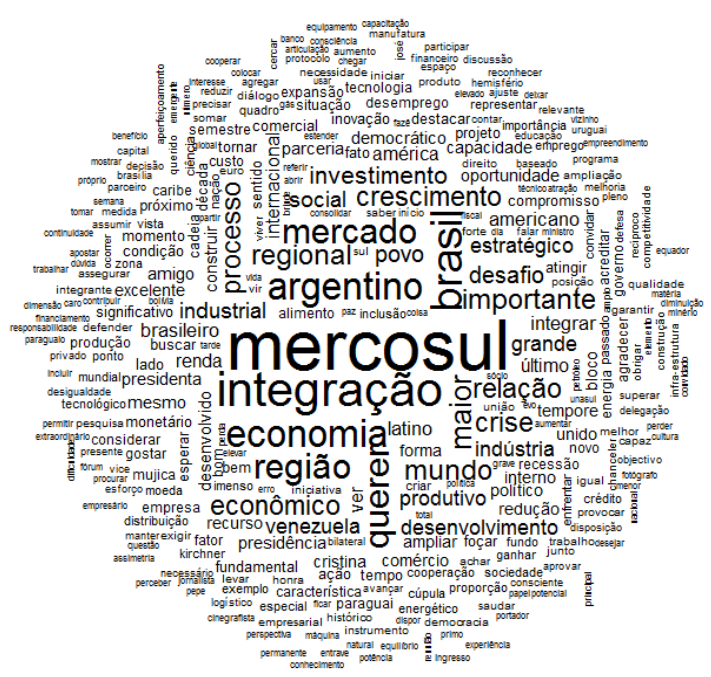


6.1.3. Dilma - 2013

Figura 3 - As 350 palavras mais faladas por Dilma em 2013

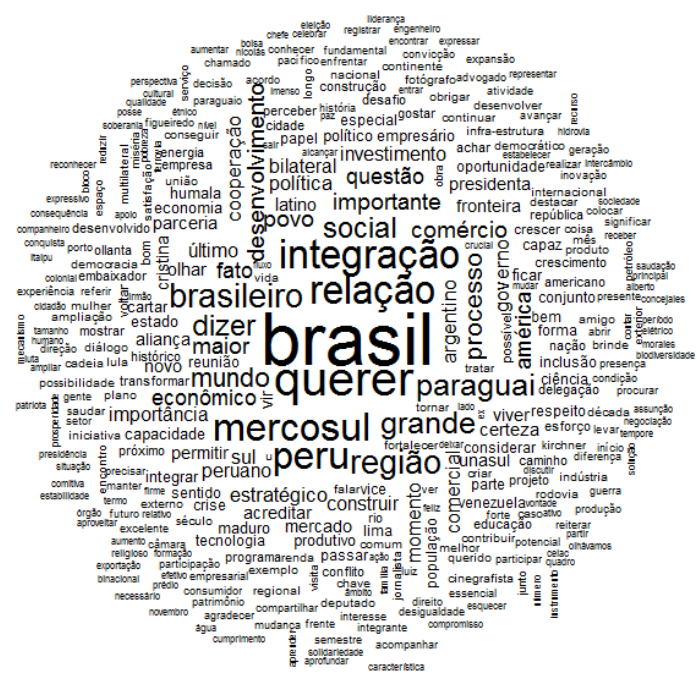

6.1.4. Dilma - 2014

Figura 4 - As 350 palavras mais faladas por Dilma em 2014

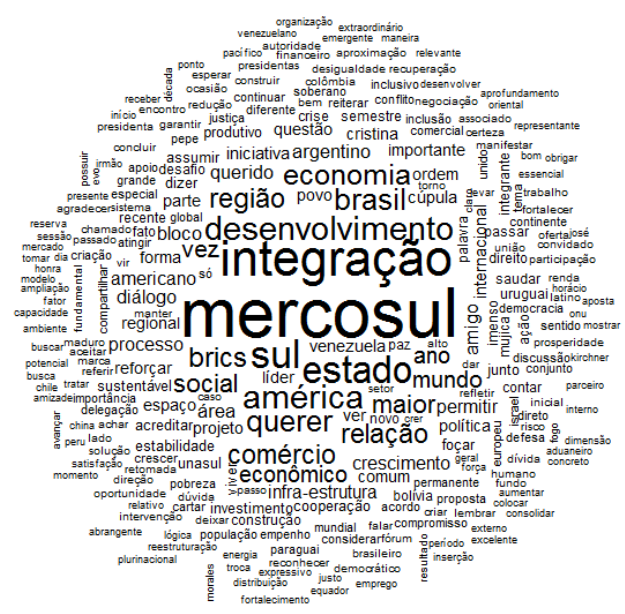




\subsubsection{Dilma - 2015}

Figura 5 - As 350 palavras mais faladas por Dilma em 2015

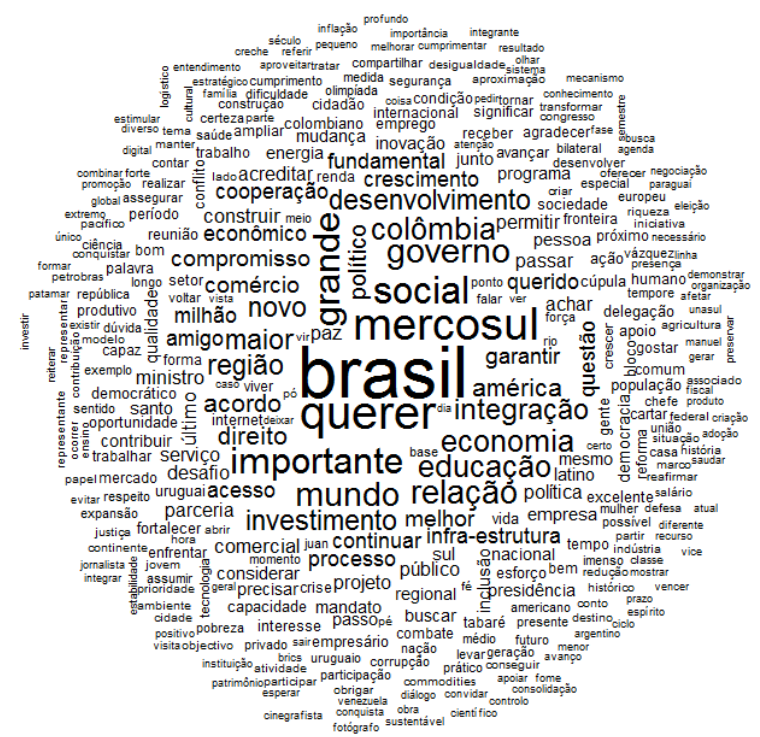

6.1.6. Dilma - 2016

Figura 6 - As 350 palavras mais faladas por Dilma em 2016 


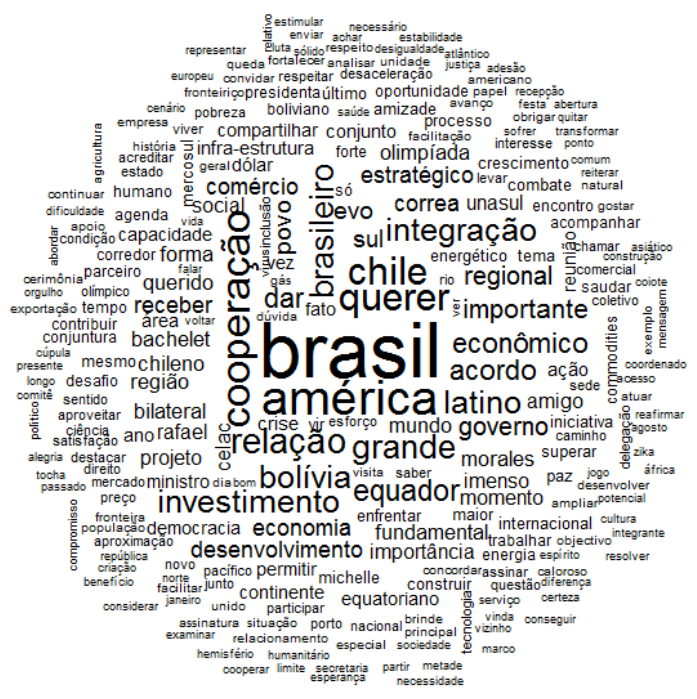

\subsubsection{Temer - 2016}

Figura 7 - As 350 palavras mais faladas por Temer em 2016

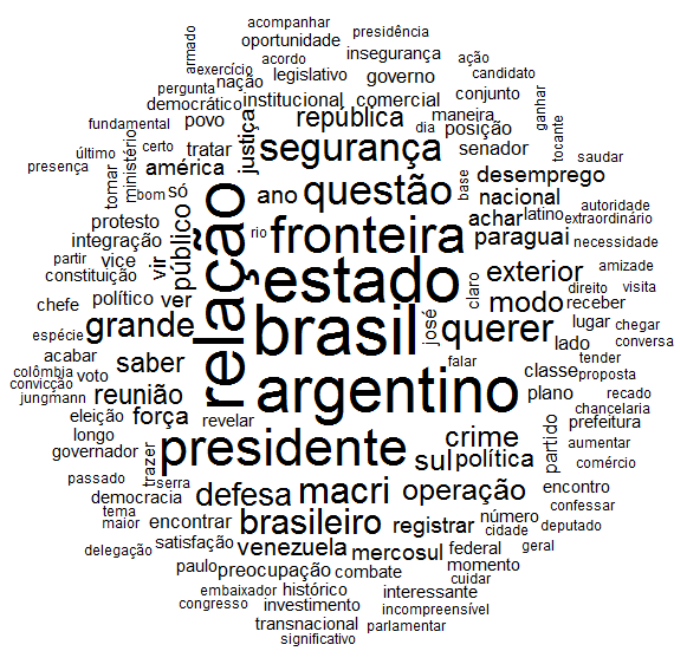

6.1.8. Temer -2017 
